\title{
Pharmacokinetics of oseltamivir in infants under the age of 1 year
}

\author{
Rashmi Dixit ${ }^{1,2^{*}}$, Slade Matthews ${ }^{2}$, Gulam Khandaker ${ }^{1}$, Karen Walker ${ }^{1,2}$, Marino Festa ${ }^{1,2}$ and Robert Booy ${ }^{1,2}$
}

\begin{abstract}
Background: Oseltamivir is the only antiviral treatment recommended for influenza in young children over the age of 1 year. There is scant data on oseltamivir pharmacokinetics (PK) in infants $<1$ year. We set out to perform PK measurements in infants who received oseltamivir.

Methods: This study was a prospective, uncontrolled, open label evaluation of the pharmacokinetics of oseltamivir metabolism, safety of oseltamivir, viral clearance in infants $<12$ months diagnosed with influenza by nasopharyngeal influenza nucleic acid antigen test (NAAT). Blood levels of the prodrug oseltamivir and its active carboxylate were measured prior to a dose of oseltamivir and at 4 time points afterwards, to calculate $C_{\max }(\mathrm{ng} / \mathrm{mL}), T_{\max }(\mathrm{h})$, $\mathrm{AUC}_{0-\mathrm{t}}(\mathrm{ng} \mathrm{h} / \mathrm{mL})$ and time for $\mathrm{AUC}(\mathrm{h})$.

Results: Four children with influenza A received oral oseltamivir, $2.35-3 \mathrm{mg} / \mathrm{kg} / \mathrm{dose}$. This dose range produced a target oseltamivir carboxylate plasma concentration in excess of the proposed 12-h target AUC of $3800 \mathrm{ng} \mathrm{h} / \mathrm{mL}$, selected from earlier studies to avert resistance. One patient developed GIT adverse event: dry retching.

Conclusion: Oseltamivir was well tolerated at a dose of $2.35-3 \mathrm{mg} / \mathrm{kg} /$ dose twice a day in infants under the age of 1 year. In general agreement with earlier data, these doses produced a target oseltamivir carboxylate plasma exposure in excess of the proposed 12-h target exposure of AUC equal to $3800 \mathrm{ng} \mathrm{h/mL} \mathrm{in} \mathrm{two} \mathrm{patients.} \mathrm{The} \mathrm{limited} \mathrm{plasma}$ concentration data in the remaining two patients were not inconsistent with the target exposure being reached.
\end{abstract}

Keywords: Oseltamivir, Infants, Influenza, Paediatrics

\section{Background}

Infants and young children are particularly prone to influenza morbidity [1-3]. Influenza morbidity in young children and infants ranges from school absenteeism to acute respiratory distress requiring hospitalisation, and can result in death from complications [1]. Oseltamivir is currently the only antiviral treatment recommended in young children, usually for those aged 1-5 years [4-6]. It inhibits the envelope protein neuraminidase, blocking release of viral progeny from infected cells, preventing subsequent entry into uninfected cells [7]. If commenced within $48 \mathrm{~h}$ of symptom onset, oseltamivir reduces both duration and complications of influenza [8,9], although some dispute this $[10,11]$. In December 2012, the use of

\footnotetext{
*Correspondence: rashmid@uni.sydney.edu.au

2 The University of Sydney, Sydney, Australia

Full list of author information is available at the end of the article
}

oseltamivir for influenza treatment, but not for prophylaxis, was approved by the FDA for infants as young as 2 weeks, previously having temporary approval for use in infancy during the 2009 pandemic, from April 2009 to June 2010 [12, 13]. Routine use of oseltamivir in infants $<1$ year of age has been limited by both a lack of pharmacokinetic (PK) data and concern about adverse events [14-17].

The ontogeny of pharmacokinetic functions has potential dosing implications in infants $[18,19]$. Oo et al. proposed a dose of $2-3 \mathrm{mg} / \mathrm{kg}$ in infants 6-12 months of age, given that renal and hepatic clearance of oseltamivir adjusted for body surface area reach adult levels by $6-9 / 12$ of age [20]. The only known published data regarding oseltamivir pharmacokinetics in infants $<1$ year old is by Kimberlin et al. [21]. They recommended doses of $3.0 \mathrm{mg} / \mathrm{kg}$ twice a day (BID) for infants less than 8 months old, and $3.5 \mathrm{mg} / \mathrm{kg}$ BID for 
infants 9-11 months, based on evidence that these doses achieve an oseltamivir carboxylate $12 \mathrm{~h}$ area-under-thecurve (AUC) target of $3800 \mathrm{ng} \mathrm{h} / \mathrm{mL}$, and promote less oseltamivir resistance than lower doses [21-24]. The FDA recommends $3 \mathrm{mg} / \mathrm{kg}$ BID for infants $<1$ year of age [25].

During the 2011 influenza season at the Children's Hospital, Westmead (CHW) in Sydney, Australia, pharmacokinetic data was collected from a series of four infants admitted to intensive care and treated with oseltamivir.

\section{Methods}

\section{Study population}

Infants aged $<12$ months who warranted treatment with oseltamivir for influenza-like illness were included. The Sydney Children's Hospitals Network Human Research Ethics Committee provided ethics approval (approval number: HREC/10/CHW/61). All patients or caregivers signed informed consent forms.

\section{Study design and end points}

This study was a prospective, open label evaluation of the pharmacokinetics of oseltamivir metabolism, safety of oseltamivir, viral clearance. The oseltamivir dose prescribed was at the attending clinician's discretion.

\section{Pharmacokinetic analysis}

Specific recommendations were made for the timing of blood samples to measure levels of oseltamivir and oseltamivir carboxylate. However, to minimize the number of tests and patient discomfort, samples were collected at the same time as clinically required samples, whenever possible. Recommended times of sample collection were within $15 \mathrm{~min}$ prior to an oseltamivir dose, $1 \mathrm{~h} \pm 15 \mathrm{~min}, 2-3 \mathrm{~h}, 5-7 \mathrm{~h}$ and $10-12 \mathrm{~h}$ post dose. The blood volume required for plasma level determination was $500 \mu \mathrm{L}$. Blood was collected into a sodium fluoride/ EDTA collection tube, placed on ice and centrifuged $\left(1500 \mathrm{~g}\right.$ at $4{ }^{\circ} \mathrm{C}$ for $\left.10 \mathrm{~min}\right)$. Plasma was stored at -70 to $-80{ }^{\circ} \mathrm{C}$ before despatch to the laboratory (PRA Early Development Services, Inc. Kansas, USA). Oseltamivir and oseltamivir carboxylate concentrations were determined by high-performance liquid chromatography with tandem mass spectrometric detection [18].

We adopted a desirable target exposure value proposed by Kimberlin of an $\mathrm{AUC}_{12}$ for oseltamivir carboxylate of $3800 \mathrm{ng} \mathrm{h} / \mathrm{mL}$ [21]. For computational purposes, concentrations at $\mathrm{t}=-15 \mathrm{~min}$ were taken as concentration at zero time. Non-compartmental analysis was conducted using PKSolver, a published pharmacokinetic analysis Excel plugin [26] to obtain estimates of exposure including $\mathrm{AUC}_{0-\mathrm{t}}$ and $\mathrm{C}_{\max }$. A set of 5 time-points from zero to $10 \mathrm{~h}$ in the 6th dose cycle was available for two of the four patients while for the other two patients only two time-points were available each, for one patient in the 7th dose-cycle and for the other patient in the 8th dose-cycle. It can be assumed that the patients were at steady-state by this time hence the sparsely sampled data may still give an impression of the exposure to oseltamivir carboxylate in these patients.

\section{Virological analysis}

Each nasopharyngeal swab or aspirate was obtained using a sterile synthetic tip swab, with a plastic or aluminium shaft, and inserted into vials containing sterile viral transport medium. These were collected at treatment initiation and analysed at the Children's Hospital, Westmead; Sydney, Australia. Influenza was diagnosed and strain type determined using nucleic acid amplification testing (NAAT) by polymerase chain reaction (PCR).

\section{Safety evaluation}

An adverse event was defined as any untoward medical occurrence in a patient which may or may not have a causal relationship with the administered oseltamivir. The following biomarkers were assessed during oseltamivir treatment and compared to pre-treatment levels: serum creatinine, electrolytes, liver transaminases (AST, ALT), alkaline phosphatase, total bilirubin level and full blood count.

\section{Results}

Four children received oral oseltamivir: three at $3 \mathrm{mg} / \mathrm{kg}$ twice a day (bd) and one at $2.35 \mathrm{mg} / \mathrm{kg}$ bd.

All four patients were infected with influenza A, patients $1-3$ were $\mathrm{H} 1 \mathrm{~N} 1$ and the strain was not documented for the patient 4 .

The following table presents the pharmacokinetic parameters for oseltamivir in these four patients (Table 1).

From the $\mathrm{AUC}_{0-\mathrm{t}}$ estimates, the first two patients (1 and 2) attained oseltamivir carboxylate plasma concentrations in excess of the proposed 12-h target AUC value for antiviral therapy during the 0 to approximately 10 -h period; it can be surmised that a 0-12 h AUC exposure value would also be in excess of the proposed therapeutic target given these $\mathrm{AUC}_{0-\mathrm{t}}$ values (Fig. 1). The two patients with only two samples per dose cycle were exposed to 1747 and $2156 \mathrm{ng} \mathrm{h} / \mathrm{mL}$ for periods of 2.3 and $6.5 \mathrm{~h}$, respectively. These levels of exposure are not inconsistent with adequate oseltamivir carboxylate exposure sufficient to provide effective therapy given the proposed target $\mathrm{AUC}_{12}$ of $3800 \mathrm{ng} \mathrm{h} / \mathrm{mL}$, but further plasma time points would have allowed for confirmation. 


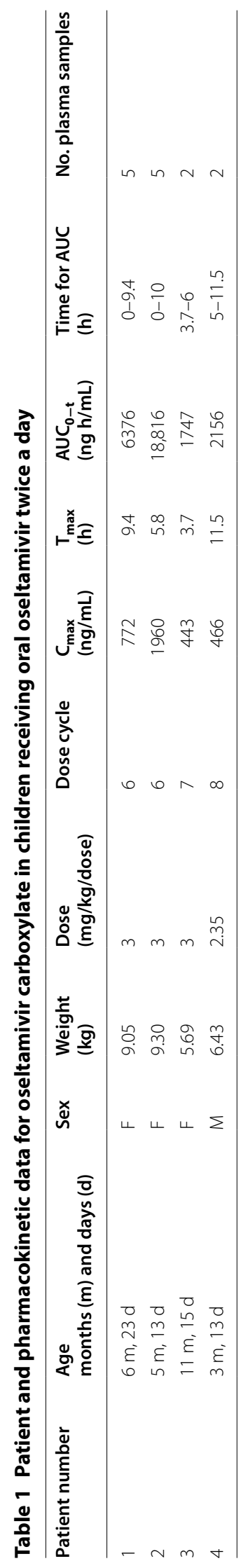




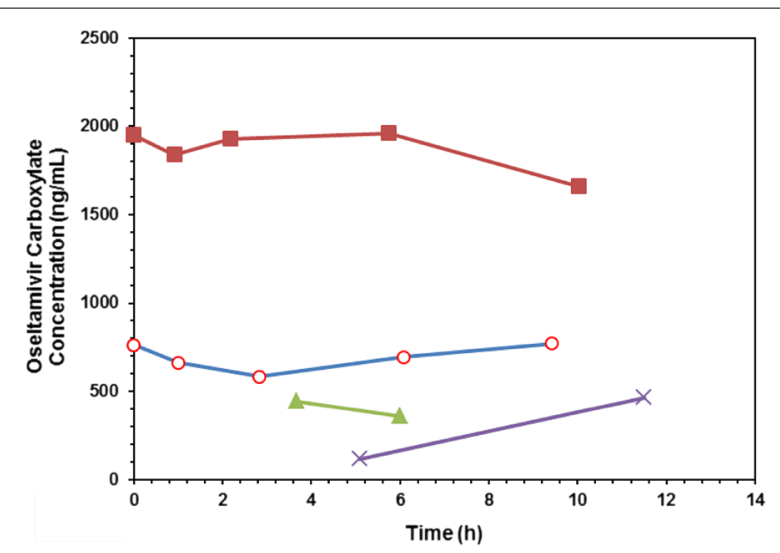

Fig. 1 Plasma-time curves for oseltamivir carboxylate in four infants

All patients recovered from acute influenza during their intensive care unit admissions. One infant suffered an adverse event: self-limited dry retching (Table 2).

\section{Discussion}

Our results are consistent with the proposition that a dose of $2.35-3 \mathrm{mg} / \mathrm{kg}$ produced a target oseltamivir carboxylate plasma concentration in excess of the proposed 12-h target AUC of $3800 \mathrm{ng} \mathrm{h} / \mathrm{mL}$.

Oseltamivir is well absorbed from an early age. Animal studies demonstrate a rapid increase of the transport protein at birth, and a widespread distribution for oseltamivir including good penetration of lung tissue, the middle ear and the nasal mucosa [27]. It is metabolized to the active metabolite oseltamivir carboxylate by the liver carboxylesterase HCE1 [19, 27]. Production of
HCE1 is lower in foetuses than in infants $<1$ year of age, who in turn have lower gene transcription than children 1-10 years [18]. However, much inter-individual variability exists, particularly in the younger age groups. Young children have greater proportionate extracellular fluid and thus a greater volume of distribution (VD) of oseltamivir carboxylate, resulting in a lower circulating plasma concentration compared to older children and adults [27]. Oseltamivir carboxylate is not extensively protein bound and, thus, immaturity of plasma protein levels does not impact on VD [27]. Animal studies indicate good penetration of oseltamivir carboxylate into respiratory tissues [19]. Oseltamivir has been linked to neuropsychiatric side effects in children and young adults, especially in Japan, although it is unclear whether the encephalopathy was induced by influenza or by its treatment $[28,29]$. Both rat and human foetus studies showed certain central nervous system (CNS) efflux pumps to be in low numbers at birth and increase with age, whilst others are present from the second trimester [19]. There was, however, no accumulation of oseltamivir carboxylate in the brains of healthy rats. Oseltamivir is filtered and actively excreted from the renal tubules using OAT transporter proteins [27]. Clearance function of these proteins is low at birth and increases over the first year of life, which may lead to reduced oseltamivir clearance in neonates [27]. Oo et al. demonstrated that oseltamivir carboxylate clearance adjusted for body surface area (BSA) reached adult levels by $6-9$ months of age, whilst a higher BSA-to weight ratio in those 1-2 years resulted in higher clearance and consequently lower peak plasma concentration $\left(C_{\text {max }}\right)$, time to reach $C_{\max }\left(\mathrm{T}_{\max }\right)$ and AUC compared to those $3-5$ years

Table 2 Adverse events (AE) in children receiving oral oseltamivir

\begin{tabular}{|c|c|c|c|c|}
\hline Patient number & $\begin{array}{l}\text { Age } \\
\text { months (m) } \\
\text { and days }(d)\end{array}$ & Comorbidities & Clinical AE & Laboratory changes \\
\hline 1 & $6 \mathrm{~m}, 23 \mathrm{~d}$ & Tetralogy of Fallot & $\begin{array}{l}\text { D1 } \\
\text { Dry-retching }\end{array}$ & $\begin{array}{l}\text { Day } 1 \text { bloods: raised creatinine }(48 \mathrm{mmol} / \mathrm{L}) \\
\text { and AST ( } 66 \mathrm{mmol} / \mathrm{L}) \\
\text { Attributed to cardiac condition } \\
\text { Normalised after frusemide dose during } \\
\text { course of oseltamivir }\end{array}$ \\
\hline 2 & $5 \mathrm{~m}, 13 \mathrm{~d}$ & $\begin{array}{l}\text { Albright's osteodystrophe } \\
\text { Hypothyroidism } \\
\text { Hypoparathyroidism } \\
\text { GORD } \\
\text { Severe OSA due to epiglottis dystrophy }\end{array}$ & Nil & Nil \\
\hline 3 & $11 \mathrm{~m}, 15 \mathrm{~d}$ & $\begin{array}{l}\text { Streptococcus pneumoniae bacteraemia, } \\
\text { pneumonia, meningitis } \\
\text { Parainfluenza 3/rhinovirus/enterovirus } \\
\text { co-infection } \\
\text { Developed HUS }\end{array}$ & Nil & $\begin{array}{l}\text { Baseline bloods normal } \\
\text { D2 of oseltamivir: rising creatinine, urea, } \\
\text { AST/ALT/GGT } \\
\text { All parameters normalised } 10 \text { days after first } \\
\text { dose } \\
\text { Laboratory abnormalities attributed to HUS }\end{array}$ \\
\hline 4 & $3 \mathrm{~m}, 13 \mathrm{~d}$ & Exomphthalmos & Nil & $\mathrm{Nil}$ \\
\hline
\end{tabular}


[20]. Kimberlin et al. achieved their target AUC with doses of $3 \mathrm{mg} / \mathrm{kg}$ in those up to 9 months of age whereas those 9-11 months of age required a higher dose of $3.5 \mathrm{mg} / \mathrm{kg}$, due to greater oseltamivir carboxylate clearance over the first year of life [21]. Thus, oseltamivir clearance may peak around 12 months, and then reduce after 3 years.

There was one GIT side effect (dry-retching) from oseltamivir in our cohort. Laboratory anomalies were attributable to comorbidities. Likewise, a dose of $3-3.5 \mathrm{mg} / \mathrm{kg}$ of oseltamivir was well tolerated in 87 infants with no premature drug discontinuation [21]. Of eight adverse events (AE) deemed related to oseltamivir (9.1\%), five were emesis, two developed a rash and one developed a serious AE: cutaneous hypersensitivity. There were no CNS AE. In another trial, 11 infants who received a rather high median dose of $5.5 \mathrm{mg} / \mathrm{kg} /$ dose of oseltamivir suffered no serious adverse events, and all completed the course [30]. Two developed a rash, two gastrointestinal side effects and three had transiently raised liver transaminases that normalised within 2 weeks of completing therapy. In a report of 35 patients $<1$ year of age who received oseltamivir, no AE occurred and no effect on liver function was detected [31]. In a report of 5 premature infants, mean gestational age 31 weeks, who received oseltamivir at 2-3 $\mathrm{mg} / \mathrm{kg} / \mathrm{dose}$, there were no treatment related AE [32].

\section{Conclusion}

Oseltamivir was well tolerated at a dose of $2.35-3 \mathrm{mg} / \mathrm{kg} /$ dose twice a day in infants under the age of 1 year. These doses were confirmed to produce a target oseltamivir carboxylate plasma exposure in excess of the proposed 12-h target exposure of AUC $3800 \mathrm{ng} \mathrm{h} / \mathrm{mL}$ in two patients and the limited plasma concentration data in the remaining two patients were not inconsistent with the target exposure being reached.

\section{Authors' contributions}

$\mathrm{RD}, \mathrm{GK}$, and RB contributed to the design of the study. RD, MF, GK and KW contributed to data acquisition. RD and SM performed pharmacokinetic analysis and data interpretation. RD, GB, RB and SM all contributed to writing of final manuscript. All authors read and approved the final manuscript.

\section{Author details}

${ }^{1}$ The Children's Hospital, Westmead, Sydney, Australia. ${ }^{2}$ The University of Sydney, Sydney, Australia.

\section{Acknowledgements}

The authors wish to acknowledge the participants and their families for their generous support.

\section{Competing interests}

The authors declare that they have no competing interests. Authors Booy and Khandaker have worked on unrelated projects funded by Roche in the past but have not received any form of remuneration or in kind support from the company. Author Festa has received funding for Intensive Care Unit (ICU) equipment unrelated to this study.

Received: 10 March 2016 Accepted: 15 August 2016

Published online: 05 September 2016
References

1. Munoz FM (2002) The impact of influenza in children. Semin Pediatr Infect Dis 13:72-78

2. Milne BG, Williams S, May MLA et al (2004) Influenza A associated morbidity and mortality in a Paediatric Intensive Care Unit. Commun Dis Intell 28:504-509

3. The ANZIC Influenza Investigators (2009) Critical care services and 2009 H1N1 influenza in Australia and New Zealand. N Engl J Med 361:1925-1934

4. Fiore AE, Fry A, Shay D et al (2011) Antiviral agents for the treatment and chemoprophylaxis of influenza-recommendations of the Advisory Committee on Immunization Practices (ACIP). MMWR Recomm Rep 60:1-24

5. Communicable Diseases Network Australia. Influenza infection CDNA National Guidelines for Public Health Units. Series of national guidelines. 2011

6. Health Protection Services (2012) HPA guidance on use of antiviral agents for the treatment and prophylaxis of influenza. Version 3. Health Protection Agency

7. Bardsley-Elliot A and Noble S (1999) Oseltamivir. Drugs 58:851-860; discussion 861-852

8. Whitley RJ, Hayden FG, Reisinger KS et al (2001) Oral oseltamivir treatment of influenza in children. Pediatr Infect Dis J 20:127-133

9. Heinonen S, Silvennoinen $\mathrm{H}$, Lehtinen P et al (2010) Early oseltamivir treatment of influenza in children 1-3 years of age: a randomized controlled trial. Clin Infect Dis 51:887-894

10. Godlee R (2012) Open letter to Roche about oseltamivir trial data. BMJ $345: e 7305$

11. Jefferson Tet al (2009) Neuraminidase inhibitors for preventing and treating influenza in healthy adults: systematic review and meta-analysis. BMJ 339:b5106

12. Buck ML(2012) An update on oseltamivir use in infants and children. Pediatr Pharm 18(9)

13. U.S. Food and Drug Administration (2012) FDA expands Tamiflu's use to treat children younger than 1 year. http://www.fda.gov/NewsEvents/ Newsroom/PressAnnouncements/ucm333205.htm

14. Kimberlin DW, Shalabi M, Abzug MJ et al (2010) Safety of oseltamivir compared with the adamantanes in children less than 12 months of age. Pediatr Infect Dis J 29:195-198

15. Okamoto S, Kamiya I, Kishida K et al (2005) Experience with oseltamivir for infants younger than 1 year old in Japan. Pediatr Infect Dis J 24:575-576

16. Siedler K, Skopnik H (2010) Oseltamivir for treatment of influenza in infants less than one year: a retrospective analysis. Pediatr Infect Dis J 29:495-498

17. Tamura D, Miura T, Kikuchi Y (2005) Oseltamivir phosphate in infants under 1 year of age with influenza infection. Pediatr Int 47:484

18. Yang D, Pearce RE, Wang X et al (2009) Human carboxylesterases HCE1 and HCE2: ontogenic expression, inter-individual variability and differential hydrolysis of oseltamivir, aspirin, deltamethrin and permethrin. Biochem Pharmacol 77:238-247

19. Abdel-Rahman SM, Newland JG, Kearns GL (2011) Pharmacologic considerations for oseltamivir disposition: focus on the neonate and young infant. Paediatr Drugs 13:19-31

20. Oo C, Hill G, Dorr A, Liu B, Boellner S, Ward P (2003) Pharmacokinetics of anti-influenza prodrug oseltamivir in children aged 1-5 years. Eur $\mathrm{J}$ Clin Pharmacol 59(5-6):411-415 (Epub 2003 Aug 9)

21. Kimberlin DW, Acosta EP, Prichard MN et al (2013) Oseltamivir pharmacokinetics, dosing, and resistance among children aged $<2$ years with influenza. J Infect Dis 207(5):709-720

22. Hayden FG, Belshe R, Villanueva C, Lanno R, Hughes C, Small I, Dutkowski R, Ward P, Carr J (2004) Management of influenza in households: a prospective, randomized comparison of oseltamivir treatment with or without postexposure prophylaxis. J Infect Dis 189(3):440-449 (Epub 2004 Jan 26)

23. Whitley RJ, Hayden FG, Reisinger KS, Young N, Dutkowski R, Ipe D, Mills $R G$, Ward P (2001) Oral oseltamivir treatment of influenza in children. Pediatr Infect Dis J. 20(2):127-133

24. Kiso M, Mitamura K, Sakai-Tagawa Y, Shiraishi K, Kawakami C, Kimura K, Hayden FG, Sugaya N, Kawaoka Y (2004) Resistant influenza A viruses in children treated with oseltamivir: descriptive study. Lancet 364(9436):759-765 
25. US (2012) Food and Drug Administration. FDA expands Tamiflu's use to treat children younger than 1 year. http://www.fda.gov/NewsEvents/ Newsroom/PressAnnouncements/ucm333205.htm

26. Zhang Y, Huo M, Zhou J, Xie S (2010) PKSolver: an add-in program for pharmacokinetic and pharmacodynamic data analysis in Microsoft Excel. Comput Methods Programs Biomed 99(3):306-314

27. He G, Massarella J, Ward P (1999) Clinical pharmacokinetics of the prodrug oseltamivir and its active metabolite Ro 64-0802. Clin Pharmacokinet 37:471-484

28. Maxwell SR (2007) Tamiflu and neuropsychiatric disturbance in adolescents. BMJ 334:1232-1233

29. Dalvi PS, Singh A, Trivedi HR, Mistry SD, Vyas BR (2011) Adverse drug reaction profile of oseltamivir in children. J Pharmacol Pharmacother. 2(2):100-103
30. Pannaraj PS, Tam B, Akan D (2011) Oseltamivir treatment and prophylaxis in a neonatal intensive care unit during a $2009 \mathrm{H} 1 \mathrm{~N} 1$ influenza outbreak. J Perinatol 31(7):487-493. doi:10.1038/jp.2010.159 (Epub 2011 Jan 13)

31. Kara A, Karadăg-Oncel E, Ozkaya-Parlakay A, Korukluoğlu G, Bağdat A, Celik M, Ceyhan M, Cengiz AB (2012) Oseltamivir use in infants under one year of age: are there still unanswered questions? Turk J Pediatr 54(1):25-29

32. Holgate Sandi L, Bekker Adrie, Rabie Helena, Cotton Mark F (2012) Oseltamivir use in low-birth weight infants during the $2009 \mathrm{nH} 1 \mathrm{~N} 1$ influenza A outbreak in the Western Cape. South Africa. J Trop Pediatr 58(2):102-106

\section{Submit your manuscript to a SpringerOpen ${ }^{\circ}$ journal and benefit from:}

- Convenient online submission

- Rigorous peer review

- Immediate publication on acceptance

- Open access: articles freely available online

- High visibility within the field

- Retaining the copyright to your article 